\title{
A Combination Atmospheric Pressure LC/MS:GC/MS Ion Source: Advantages of Dual AP-LC/MS:GC/MS Instrumentation
}

\author{
Charles N. McEwen and Richard G. McKay \\ DuPont Corporate Center for Analytical Sciences, Wilmington, Delaware, USA
}

\begin{abstract}
Modification of commercial LC/MS instrumentation to allow both atmospheric pressure (AP) LC/MS and GC/MS is described. Advantages of this additional capability versus LC/MS alone include higher chromatographic resolution in the GC versus LC mode, greater peak capacity for complex mixture analysis, higher sensitivity for a variety of volatile compounds, and the ability to observe compounds of low polarity that are not readily observed in LC/MS. Advantages over conventional GC/MS include the ability to use higher carrier gas flow and shorter columns for passing less volatile materials through the gas chromatograph, selective ionization, and rapid switching between positive and negative ion modes. Other advantages include application of the enhanced capabilities of LC/MS instrumentation to GC/MS analyses such as cone voltage fragmentation, $\mathrm{MS}^{\mathrm{n}}$, high mass resolution, and accurate mass measurement. Limitations of APGC/MS include the inability to observe saturated hydrocarbon and certain other highly nonpolar compounds and less odd-electron fragmentation for computer aided library searching. For some analyses, the limitation related to ionization of highly nonpolar compounds is advantageous, as is the simplified mass spectrum and easy molecular weight identification that results from less fragmentation observed in the AP ionization mode. (J Am Soc Mass Spectrom 2005, 16, 1730-1738) (C) 2005 American Society for Mass Spectrometry
\end{abstract}

$\mathrm{G}$ as chromatography interfaced to mass spectrometry (GC/MS) is a well established and powerful method for the analysis of volatile and semi-volatile materials [1]. In comparison to liquid chromatography interfaced to mass spectrometry (LC/MS), GC/MS has the advantages of higher chromatographic resolution and higher peak capacity, easier quantitation with flame-ionization detection, a single mobile phase (helium), fewer issues with solubility, and separations that can be adjusted by electronic controls such as temperature programming [2]. These advantages are especially important in the study of complex mixtures. A timely example is metabolomics analysis [3].

The effluent from the GC is introduced into the vacuum of the mass spectrometer either directly from capillary fused silica columns or after a differential pumping stage for higher gas load columns. Ionization occurs under vacuum conditions either by electron ionization or by chemical ionization [1]. On the other hand, ionization in LC/MS typically occurs at atmospheric pressure and the ions are swept into the vacuum system through differentially pumped regions

Published online September 26, 2005

Address reprint requests to Dr. C. McEwen, Central Research and Development Department, DuPont Experimental Station, P.O. Box 80228, Wilmington, DE 19880-0228, USA. E-mail: charles.n.mcewen@usa.dupont.com separated by apertures or capillaries [4]. Ionization in atmospheric pressure LC/MS is by electrospray ionization (ESI) [5], corona discharge ionization [atmospheric pressure chemical ionization (APCI)] [6], photo ionization [7], or surface ionization [8]. Because ionization in GC/MS occurs under vacuum conditions and in LC/MS occurs at atmospheric pressure, the two separation methods require entirely different interfaces to the mass spectrometer and are thus usually performed on instruments dedicated to the particular chromatography method.

However, GC/MS can also be achieved under atmospheric pressure ionization conditions. APCI was initially developed by Horning et al. using ${ }^{63} \mathrm{Ni} \beta$ decay for ionization [9]. A corona discharge ion source later replaced the ${ }^{63} \mathrm{Ni}$ as the source of ionization [6]. Horning et al. were the first to interface a GC instrument to an APCI ion source $[10,11]$. Since these initial publications, a series of papers originating at the National Center for Toxicological Research in Jefferson, Arkansas, have been published in which the effluent from a gas chromatograph is ionized at atmospheric pressure [12-21]. The interface used in these experiments couple the GC to a ${ }^{63} \mathrm{Ni}$ ion source of a mass spectrometer built for APCI gas-phase studies. In particular, GC/APMS operated in the negative ion mode was demonstrated to be a highly sensitive method for detecting a number of environmentally important compounds. APCI ion 


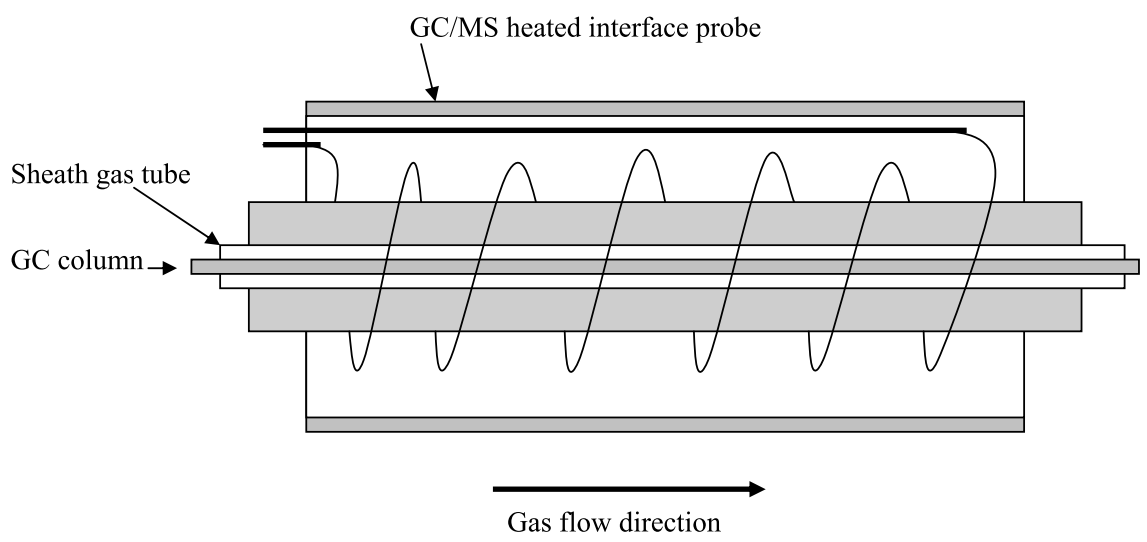

Figure 1. Diagram of the exit end of the GC/APMS interface showing the GC column extending through a heated sheath tube. Nitrogen gas flowing through the sheath tube and over the GC column heats the column uniformly to the exit tip.

sources for gas analysis have been interfaced to commercial instruments (Extranuclear Laboratories, Inc., now ABB, Inc., Norwalk, CT, [22] MDS Sciex, Concord, ON, Canada, [23, 24] and Finnigan-Mat, now ThermoFinnigan, Inc., San Jose, CA [21]). Even so, GC/ APMS never became popular, probably because of the high costs of the specialized instrumentation needed for these analyses.

APCI sources attached to mass spectrometers have also been used for gas analysis such as the determination of volatiles in breath and fragrances emulating from skin and clothing $[25,26]$. Pyrolysis with ionization of the gaseous pyrolysate has also been reported, [27] as has APCI of warfare agent simulants, [28] and organic compounds at the parts per trillion level [29]. Supercritical fluid chromatography has also been interfaced to APCI-MS [30-32]. However, the primary use of this ionization method has been as an ionization interface between liquid chromatography and mass spectrometry [11].

In recent years, atmospheric pressure mass spectrometers have proliferated, primarily because of electrospray ionization and the ease of interfacing this atmospheric pressure ionization method to liquid chromatographs [5]. In addition, many of the mass spectrometers currently used for LC/MS have capability for $\mathrm{MS}^{\mathrm{n}}$ studies and/or accurate mass measurement, capabilities that are more rare for GC/MS instrumentation.

In this paper, we introduce a simple modification of the atmospheric pressure ion sources used in LC/MS instrumentation that converts the source into a more universal ion source able to perform GC/APMS in addition to APCI, ESI, or PI LC/MS. The combination ion source can be readily adapted to most LC/MS instruments without reduction of LC/MS sensitivity. Both positive and negative ion GC/APMS spectra can be obtained with high sensitivity. In addition, all of the capabilities common with LC/MS instruments such as high-resolution and accurate mass measurement, cone voltage fragmentation, $\mathrm{MS}^{\mathrm{n}}$, and multiple reaction monitoring can be applied to GC/APMS.

\section{Experimental}

For these studies, either a Micromass LCT or QTOF I mass spectrometer (Waters Corporation, Beverly, MA) with Z-Spray ion sources were modified for dual LC/ MS:AP-GC/MS operation. For the GC/APMS studies, the GC with attached heated interface probe was aligned so that the interface probe inserted into the ion source region of a Micromass LCT or QTOF I mass spectrometers. For most experiments, the interface probe (see Figure 1) inserted into the atmospheric pressure ion source volume in the position normally occupied by the ESI or APCI probe (see Figure 2). This was done by simply replacing the source cover flange

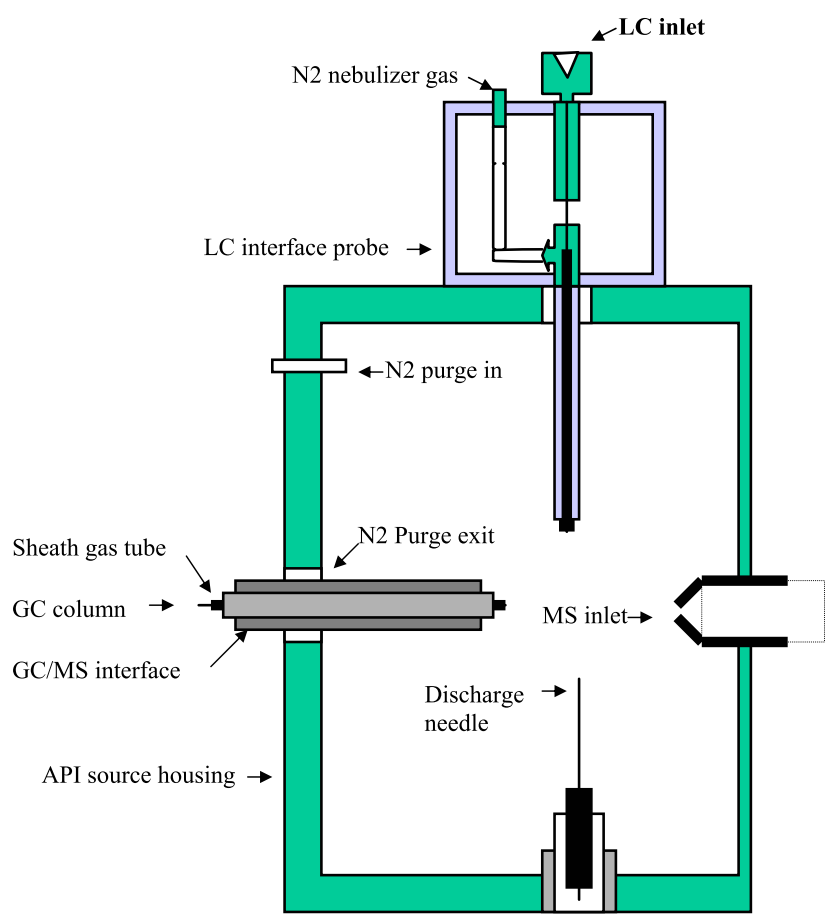

Figure 2. Diagram of an atmospheric pressure ion source designed to interface to both an LC and a GC. 


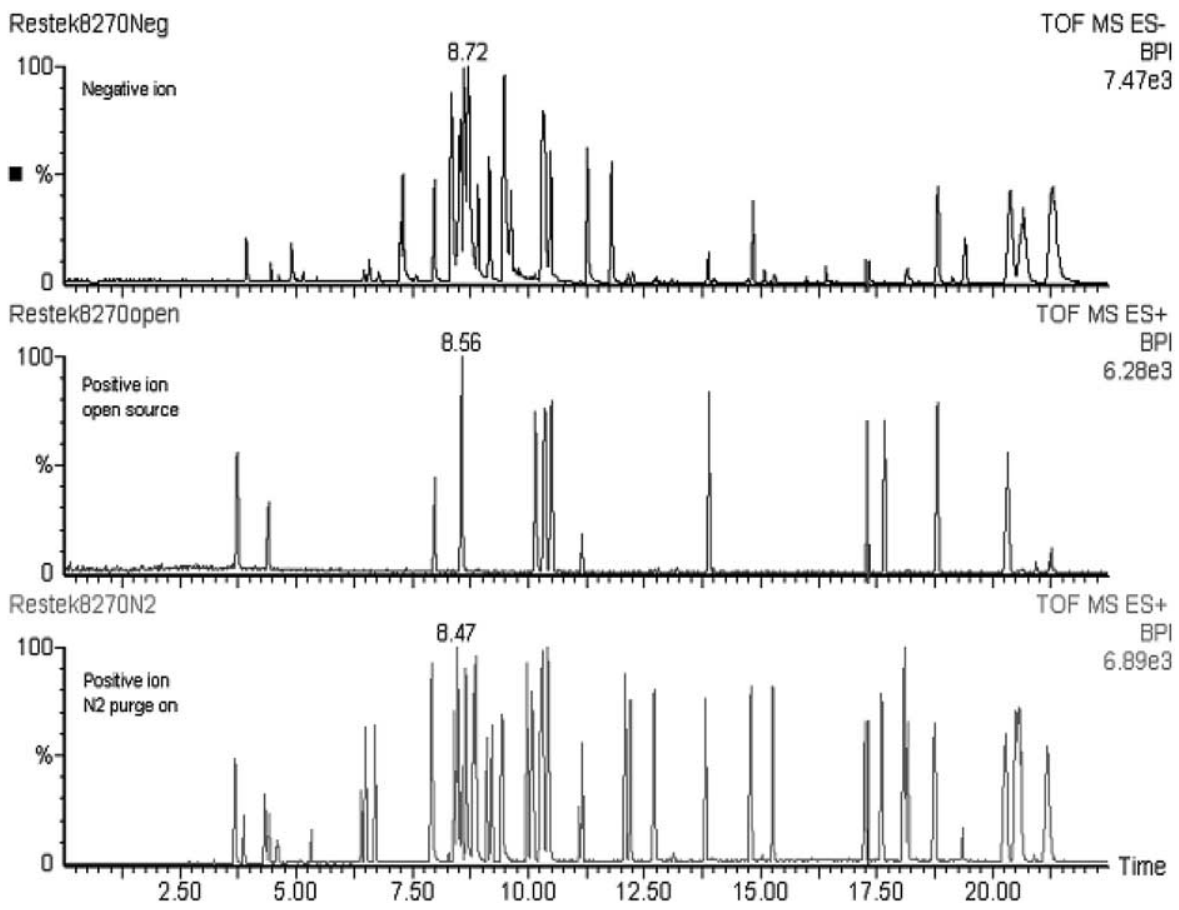

Figure 3. Base peak positive ion mass chromatograms of a Restek 8270 mixture using a dual GC/APMS:LC/MS ion source operated in the GC/MS mode. A list of the components in the mixture can be found at www.restek.com/fantasia/pdfcache/pres-2001-1037.pdf. Top: Negative ion base peak chromatogram obtained with the ion source open to the room air. Middle: Positive ion base peak chromatogram obtained with an open source and no purge gas. Bottom: Positive ion base peak chromatogram obtained with the source area sealed from the surrounding air and purged with a flow of dry nitrogen gas.

and associated ESI/APCI probe with a metal flange having ports for the GC interface probe insertion and purge gas entrance. The exit end of the GC interface probe (Figure 1) was placed at about the position that the exit end of the ESI/APCI probe normally occupies. Because the GC was situated on an adjustable cart with wheels, it was possible to adjust the probe somewhat and easily remove it for rapid switching back to the LC/MS mode. The cart also allowed the GC to be easily moved between mass spectrometers. Figure 2 shows a diagram of an alternate source design used in some experiments where both the ESI/APCI LC interface probe and the GC interface probe were inserted in the ion source. This configuration provided equivalent data to the above described arrangement when the GC interface probe was adjusted for maximum sensitivity (about $1 \mathrm{~cm}$ from the entrance aperture of the mass spectrometer).

Ionization in the atmospheric pressure ion source was produced by applying a voltage to either a Picotip emitter from New Objective, Woburn, MA, without liquid or to the standard APCI needle used in the Micromass Z-Spray APCI ion source. The Picotip was used for the arrangement in which both the LC and GC interface probes were in the ion source simultaneously (Figure 2) and was used as a convenient means of producing a corona discharge. In this arrangement, the Picotip was held in place using the Micromass nano- flow interface and the discharge voltage was applied to the nanospray source as if it were operating in the electrospray mode. The standard APCI needle was used in the ion source, described above, in which the GC interface probe replaced the $\mathrm{LC}$ probe and was operated as if it were in the APCI mode. A voltage of between 2000 and $3500 \mathrm{~V}$ was used to generate discharge conditions.

The gas chromatograph used in these studies was a Hewlett Packard 5890 Series II (Agilent Corporation, Wilmington, DE) fitted with a ThermoFinnigan (Thermo Corporation) heated interface probe. The GC was originally interfaced to a Thermo model SSQ 7000 GC/MS instrument. The exit tip of the interface probe was modified as shown in Figure 1 using ceramic tubing and Sauereisen no. 1 cement (Sauereisen Cements Company, Pittsburgh, PA). The capillary GC column was inserted through a Swagelok tee fitting (Swagelok Corporation, Solon, $\mathrm{OH}$ ) and through the interface probe and the heated sheath tube shown in Figure 1. Nitrogen gas from a liquid nitrogen dewar refrigerated container was fed through $1 / 16$ inch o.d. stainless steel tubing that coiled inside the GC oven and was connected to the center position of the Swagelok tee. Because the GC column was connected to the oven side of the tee with a gas-tight fitting, nitrogen gas from the Micromass nanoflow regulator was forced through the stainless steel tubing into the heated interface and 

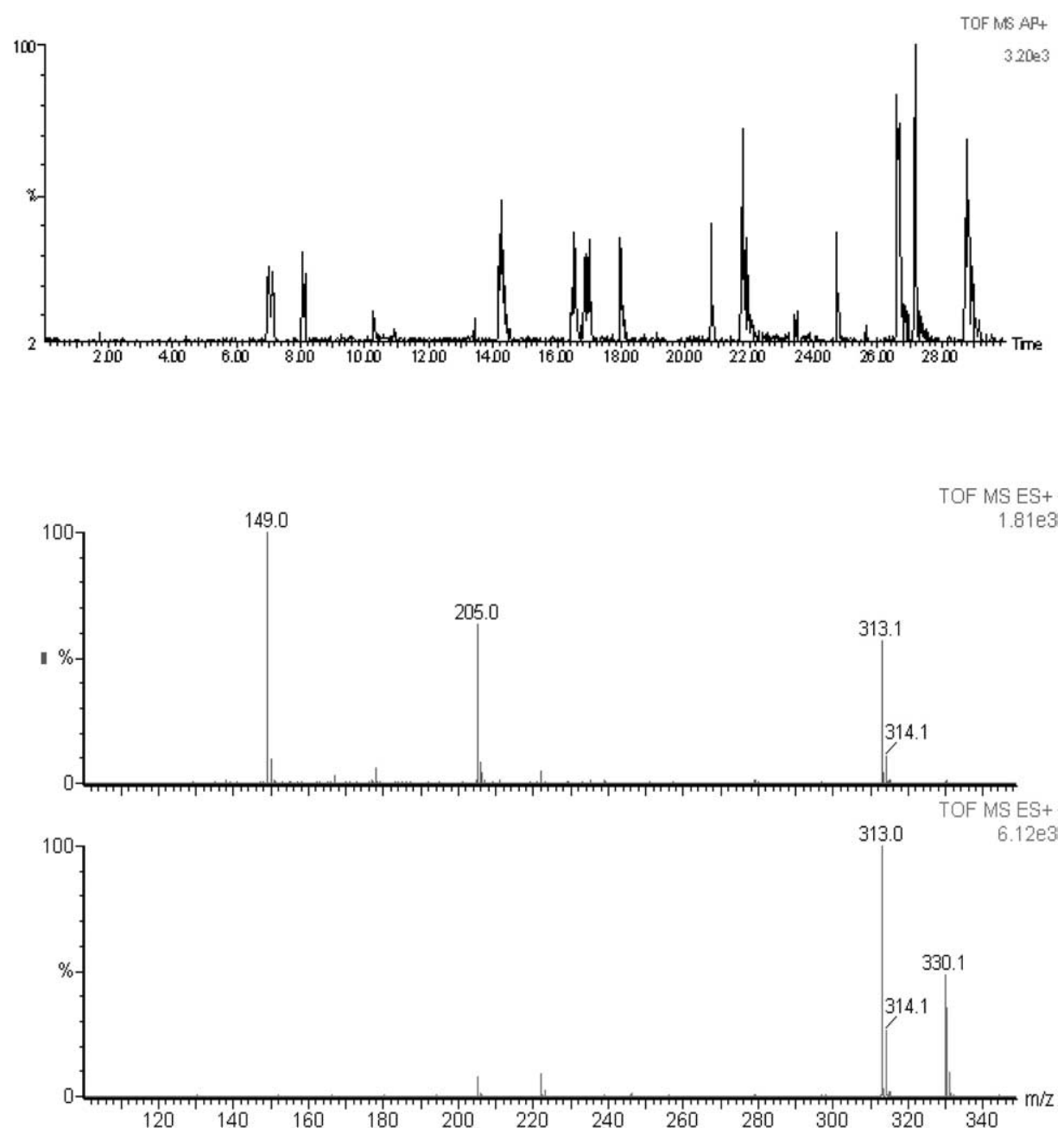

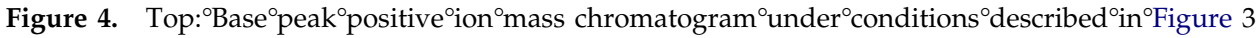
(top) ${ }^{\circ}$ except $^{\circ} \mathrm{a}^{\circ}$ vial containing ${ }^{\circ} a^{\circ}$ saturated ${ }^{\circ}$ aqueous ${ }^{\circ}$ solution ${ }^{\circ}$ of $^{\circ} \mathrm{NH}_{3}$ is open in the ion source volume. Middle: Positive ion mass spectrum of benzylbutylphthalate with the ${ }^{\circ}$ cone $^{\circ}$ voltage ${ }^{\circ} t^{\circ}{ }^{\circ}{ }^{\circ} 50^{\circ} \mathrm{V}$. ${ }^{\circ}$ Bottom: Cone voltage set at $20 \mathrm{~V}$.

through the sheath tubing shown in Figure $1 .^{\circ} \mathrm{In}^{\circ}$ this way, the heated nitrogen gas $\left(\mathrm{ca} .300^{\circ} \mathrm{C}\right)$ maintained the ${ }^{\circ} \mathrm{GC}^{\circ}{ }^{\circ}$ column $^{\circ}$ hot $^{\circ}$ to the exit tip.

It was important to condition new GC columns before initial use by heating to $300{ }^{\circ} \mathrm{C}$ with a 5 min hold several times before initial operation. Background ions could also be significantly reduced by heating the GC to MS interface to $325^{\circ} \mathrm{C}$ overnight while passing nitrogen gas through the interface. This resulted in a reduction in off-gasses from the column polyimide coating and any contaminants in the interface.

The GC was operated at a split ratio of 10:1 unless otherwise noted. One microliter of a solution of Restek 8270 Matrix spike mix [for a list of components ${ }^{\circ}$ go ${ }^{\circ}$ to ${ }^{\circ}$ www.restek.com/fantasia/pdfcache/pres-20011037.pdf $]^{\circ}\left(\right.$ Restek $^{\circ}$ Corporation, ${ }^{\circ}$ Bellefonte, PA) diluted with methylene chloride was injected for each run. The GC column used in all experiments was a Restek RTX-5 $(15 \mathrm{~m} \times 0.25 \mathrm{~mm} \times 0.25 \mathrm{um})$. The injector was set at $250{ }^{\circ} \mathrm{C}$ and the oven was maintained at $50{ }^{\circ} \mathrm{C}$ for $1 \mathrm{~min}$ after injection before temperature programmed heating at $7^{\circ} \mathrm{C} / \mathrm{min}$. for $32 \mathrm{~min}$. The interface temperature was maintained at $300{ }^{\circ} \mathrm{C}$ and the entrance aperture of the Z-Spray source was heated to $150{ }^{\circ} \mathrm{C}$. In some experiments the ion source region was enclosed except for an entrance and exit aperture for nitrogen purge gas. The nitrogen purge gas was taken from the Micromass cone gas regulator on the LCT or QTOF mass spectrometers at a flow rate of $\sim 10 \mathrm{~L} / \mathrm{h}$. In open source experiments, the glass enclosure has an opening to the room air and no purge gas was used.

For comparison with LC/APMS, the mass spectrometer was operated under the standard conditions used for LC/MS analysis in our laboratory. No attempt was made to optimize the LC conditions for the Restek 8270 analysis. For the LC, mobile phase A was 98:2:0.005 parts water:acetonitrile:formic acid and mobile phase B was 98:2:0.005 parts acetonitrile:water:formic acid. The LC column was an Agilent Zorbax SB-C18 (5 um, $2.1 \times$ $150 \mathrm{~mm}$ ). A linear gradient elution using a flow rate of $250 \mathrm{ul} / \mathrm{min}$ was run from $25 \% \mathrm{~B}$ to $100 \% \mathrm{~B}$ in $25 \mathrm{~min}$. 


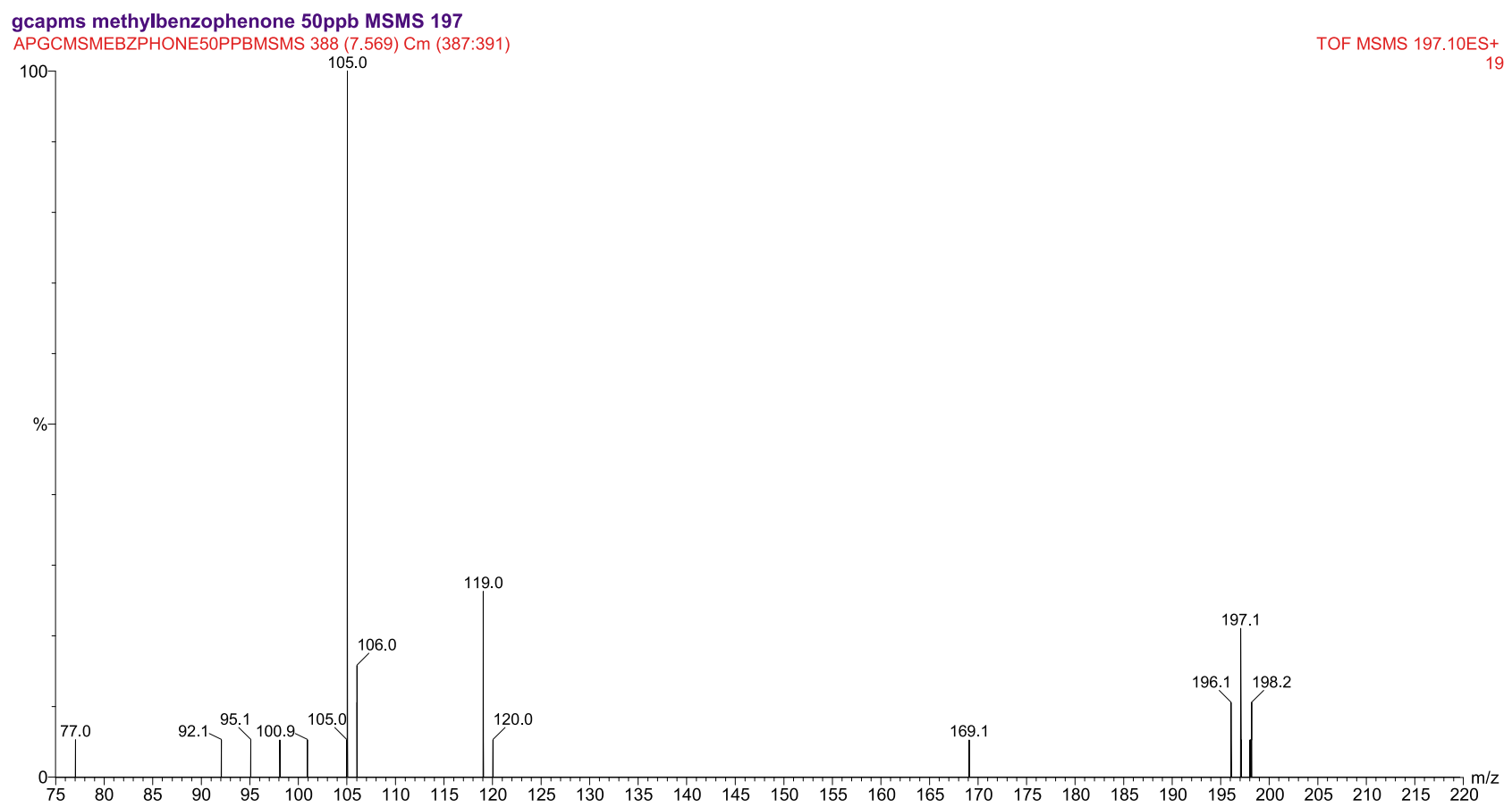

Figure 5. Positive ion GC/APMS/MS spectrum of the $\mathrm{MH}^{+}$ion of 50 pg injection of 2-methylbenzophenone using a collision energy of $24 \mathrm{~V}$ obtained on a micromass QTOF I mass spectrometer.

The mass spectrometry conditions were optimized on the $m / z 354$ ion from tri- $n$-octylamine (TOA) using $50 \%$ $B$ isocratic conditions with a flow rate of $250 \mathrm{ul} / \mathrm{min}$ from the LC with infusion of TOA into the LC flow before the ion source.

Accurate mass measurement data were acquired on a Micromass LCT using a data acquisition time of $0.45 \mathrm{~s}$ and a reset time of $0.05 \mathrm{~s}$ per spectra. Before AP-GC/MS analysis, the instrument was calibrated using a polyalanine methanol solution. The polyalanine solution was infused into the ion source under electrospray ionization conditions to generate reference ions over the mass range of 70 to $1000 \mathrm{Da}$. A single reference ion $(\mathrm{m} / \mathrm{z}$ 354.4100) from TOA was used to adjust the mass scale during AP-GC/MS acquisitions. To generate steady ion abundance for the $\mathrm{m} / \mathrm{z} 354$ reference ion, a vial containing TOA and having an adjustable wick was placed into the ion source region to allow controlled evaporation of the TOA. The volume of wick exposed to the nitrogen atmosphere was roughly adjusted to achieve the desired ion abundance.

MS/MS spectra were obtained on the Micromass QTOF I instrument using a data acquisition time of $0.7 \mathrm{~s}$ per spectra. Reproducible MS/MS spectra were obtained injecting $1 \mathrm{ul}$ of a $50 \mathrm{ppb}$ solution of 2-methylbenzophenone in acetonitrile using a 5:1 split ratio and a GC carrier gas flow of $5 \mathrm{ml} / \mathrm{min}$.

\section{Results and Discussion}

In a study designed to determine the capabilities of electrospray ionization for ionizing substances in air, we rediscovered APCI for ionization of volatile materials. Using a Picotip emitter containing a water/methanol solution, molecular ions were observed for certain volatile components that had been introduced into the air near the ion source. However, when the capillary became dry, the kinds of compounds that could be observed and the sensitivity with which they could be observed increased. It occurred to us that an LC/MS instrument could easily be converted to a combination GC/APMS-LC/APMS instrument.

Interfacing a GC to an atmospheric pressure ionization source requires that the exit of a capillary GC column be near the atmospheric pressure aperture inlet to the mass spectrometer without cold spots along the entire length of the GC column. It is especially important for less volatile compounds that the exit tip of the column be at a high enough temperature to prevent compound condensation. This is achieved by using a

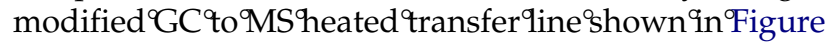
$1^{\circ} .^{\circ}$ The ${ }^{\circ}$ itrogen ${ }^{\circ}$ gas $^{\circ}$ used $^{\circ}$ to $^{\circ}$ heat ${ }^{\circ}$ the ${ }^{\circ}$ column $^{\circ}$ to ${ }^{\circ}$ the $e^{\circ}$ exit tip is taken from the nanoflow controller used for ESI operation and is heated by the GC oven and interface transfer line before flowing through the sheath tube and thus over the GC column. It was also important for less volatile compounds that the source block area be heated. With the MicroMass LCT and QTOF mass spectrometers (Waters Corporation), the maximum source temperature of $150^{\circ} \mathrm{C}$ was used. With this setup, even relatively nonvolatile compounds could be ionized without loss of chromatographic resolution.

Discharge ionization was found to be effective in either the positive or negative ion modes. A Townsend/ 
corona discharge could be generated by applying a voltage to the APCI needle or a dry Picoflow tip to generate a discharge. Trace levels of water vapor present in the atmosphere are sufficient to prevent compounds less basic than $\mathrm{H}_{2} \mathrm{O}$, or more properly, water clusters, from being ionized. The responsible ion molecule reactions are

$$
\begin{aligned}
& \mathrm{N}_{2}+\mathrm{e} \rightarrow \mathrm{N}_{2}^{+\cdot}+2 \mathrm{e} \\
& \mathrm{N}_{2}^{+\cdot}+2 \mathrm{~N}_{2} \rightarrow \mathrm{N}_{4}^{+\cdot}+\mathrm{N}_{2} \\
& \mathrm{~N}_{4}^{+\cdot}+\mathrm{H}_{2} \mathrm{O}^{\circ} \rightarrow \mathrm{H}_{2} \mathrm{O}^{+\circ}+2 \mathrm{~N}_{2^{\circ}} \\
& \mathrm{H}_{2} \mathrm{O}^{+\cdot}+\mathrm{H}_{2} \mathrm{O} \rightarrow \mathrm{H}_{3} \mathrm{O}^{+}+\mathrm{OH} \\
& \mathrm{H}_{3} \mathrm{O}^{+}+\mathrm{n}\left(\mathrm{H}_{2} \mathrm{O}\right)+\mathrm{N}_{2} \rightarrow \mathrm{H}^{+}\left(\mathrm{H}_{2} \mathrm{O}\right)_{\mathrm{n}}+\mathrm{N}_{2} \\
& \mathrm{H}^{+}\left(\mathrm{H}_{2} \mathrm{O}\right)_{\mathrm{n}}+\mathrm{A} \rightarrow \mathrm{AH}^{+}+\mathrm{nH}_{2} \mathrm{O}
\end{aligned}
$$$$
\text { (where } \mathrm{A}=\text { analyte) }
$$

Less polar compounds are ionized in the APCI ion source with increased sensitivity by purging the ion source region with a dry inert gas such as nitrogen, presumably because the water vapor and contaminants present in the ionization region are swept from the source by the flow of dry purge gas.

The base mass peak chromatograms generated from GC/APMS of a Restek 8270 mixture in the negative and positive ${ }^{\circ}{ }^{\circ}{ }^{\circ}$ modes $^{\circ}$ is $^{\circ}$ shown $^{\circ}$ in $^{\circ}{ }^{\circ}$ igure $3 .{ }^{\circ}{ }^{\circ}{ }^{\circ}$ effort ${ }^{\circ}$ was made to optimize the chromatographic conditions in these experiments. The negative ion mass spectrum obtained with the ion source open to lab air and without $a^{\circ}$ nitrogen ${ }^{\circ}$ gas $^{\circ}$ purge $^{\circ}$ is ${ }^{\circ}$ shown $^{\circ}$ in ${ }^{\circ}$ Figure $^{\circ} 3^{\circ}$ (top). ${ }^{\circ}$ The positive ion mass spectrum obtained under the same conditions ${ }^{\circ}$ is ${ }^{\circ}$ shown $^{\circ}$ in $^{\circ}$ Figure $^{\circ} 3^{\circ}$ (middle).$^{\circ}$ In $^{\circ}$ this ${ }^{\circ}$ configuration, ionization is primarily by ion-molecule proton transfer reactions between protonated water clusters and the analyte molecules (eq 6). As noted above, only compounds sufficiently basic for exothermic proton transfer from protonated water clusters are observed. ${ }^{\circ}$ Figure $^{\circ} 3^{\circ}$ (bottom $)^{\circ}$ shows ${ }^{\circ}$ the ${ }^{\circ}$ mass $^{\circ}$ chromatogram obtained when the source is enclosed except for an entrance and exit port for introduction and escape of dry nitrogen purge gas. More compounds in the Restek 8270 mixture are observed when the enclosed ion

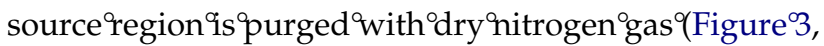
bottom) than is obtained when the source is open to room $^{\circ}$ air $^{\circ}$ (Figure ${ }^{\circ},{ }^{\circ}$ middle) ${ }^{\circ}$ I $^{\circ}{ }^{\circ}$ is $^{\circ}$ believed $^{\circ}$ that ${ }^{\circ} a^{\circ}$ dry purge gas reduces the amount of contaminants and water vapor so that ionization is primarily by $\mathrm{H}_{3} \mathrm{O}^{+}$ proton transfer and $\mathrm{N}_{2}^{+} / \mathrm{N}_{4}^{+}$charge-transfer reactions. Compounds such as naphthalene, acenaphthylene, dimethylphenol, dinitrophenol, and chloromethylphenol are ionized with good sensitivity using the nitrogen purge gas but are poorly ionized in the source that is open to air and moisture. With the nitrogen purge on, 73 of the 76 compounds listed for Restek 8270 were observed with good sensitivity in the positive ion mode. Compounds reported to be in the mixture but not observed by positive ionization are azobenzene, bis(chloroethoxy)methane, and bis(chloroisopropyl)ether. More compounds were observed in the positive ion mode than were observed under negative ion conditions, but for those compounds with a large cross section for electron capture, the negative ion sensitivity could exceed that obtained under positive ion conditions.

Contaminants can also interfere with the sensitivity and reduce the number of compounds observed. Two such sources of contaminants are the GC column bleed and the polyimide coating on the section of the GC capillary column over which the heated sheath gas passes. Conditioning the column and especially conditioning the section of column over which hot nitrogen gas passes significantly reduces background ions.

Purging the source region with dry and clean nitrogen gas increases the sensitivity for observing low polarity compounds, but adding ammonia gas by, for example, evaporation of an ammonium hydroxide solution in the source region increases the selectivity of the ionization. Only compounds more basic than ammonia or compounds capable of stable gas-phase attachment of $\mathrm{NH}_{4}^{+}$are observed. ${ }^{\circ}$ Figure ${ }^{\circ} 4^{\circ}$ (top $)^{\circ}$ shows ${ }^{\circ}$ a base peak mass chromatogram of a GC injection of the Restek 8270 mixture under conditions in which $\mathrm{NH}_{4}\left(\mathrm{NH}_{3}\right)_{\mathrm{n}}^{+}$are the dominant reagent ions. The mass spectra of one of the compounds observed in the base peak chromatogram is shown using a high cone voltage to ${ }^{\circ}$ enhance ${ }^{\circ}$ fragmentation ${ }^{\circ}$ (Figure ${ }^{\circ} 4,{ }^{\circ}$ middle) ${ }^{\circ}$ and ${ }^{\circ}$ lower cone $^{\circ}$ voltage ${ }^{\circ}$ to $^{\circ}$ minimize ${ }^{\circ}$ fragmentation ${ }^{\circ}$ (Figure ${ }^{\circ} 4$, bottom). The ion at $m / z 330$ is the $\left[\mathrm{M}+\mathrm{NH}_{4}\right]^{+}$ion of benzylbutylphthalate. Thus, using GC/APMS, molecular ions are readily identified. By adjusting the voltage between the first and second pumping stages of the AP source (cone voltage), it is possible to generate fragment ions.

The sensitivity of GC/APMS in the negative ion mode has been well demonstrated for compounds that efficiently capture electrons. For example, the detection limit for 1-nitronaphthalene was reported to be $0.3 \mathrm{pg}$ using ${ }^{\circ}$ selected ${ }^{\circ}$ ion ${ }^{\circ}$ monitoring ${ }^{\circ}[15] .{ }^{\circ}$ However, ${ }^{\circ}$ the ${ }^{\circ}$ positive ion mode of GC/APMS has been neglected and sensitivity information is not available. Using the QTOF I mass spectrometer and full scan acquisition, it was possible to construct a linear calibration curve for injections ranging from 5 to $1000 \mathrm{pg}$ of 2-methylbenzophenone injected using a split ratio of 5:1. The sensitivity ${ }^{\circ} f^{\circ} \mathrm{GC} / \mathrm{APMSMS}^{\circ} \mathrm{can}^{\circ}$ also ${ }^{\circ} \mathrm{o}^{\circ} \mathrm{dem}$ onstrated. ${ }^{\circ}$ Figure 5 shows the MS/MS CID mass spectrum of the $197 \mathrm{MH}^{+}$ ion for $1 \mathrm{ul}$ of a $50 \mathrm{ppb}$ solution of 2-methylbenzophenone injected using a 10:1 split ratio. GC/APMS can be compared to LC/MS for the Restek 8270 mixture by comparison $^{\circ}$ of $^{\circ}$ Figure $^{\circ} 1{ }^{\circ}$ with $^{\circ}$ Figure $^{\circ} 6 .{ }^{\circ}$ Figure $^{\circ} 6^{\circ}$ (top) shows the LC base peak chromatogram for $5 \times$ the amount $^{\circ}$ of $^{\circ}$ sample $^{\circ}$ injected ${ }^{\circ}$ to ${ }^{\circ}$ produce $^{\circ}$ Figure $^{\circ} 1^{\circ}$ and Figure ${ }^{\circ} 6^{\circ}$ (bottom) $)^{\circ}$ shows ${ }^{\circ}$ the ${ }^{\circ}$ diode $^{\circ}$ array $^{\circ} \mathrm{UV}^{\circ}$ spectrum 


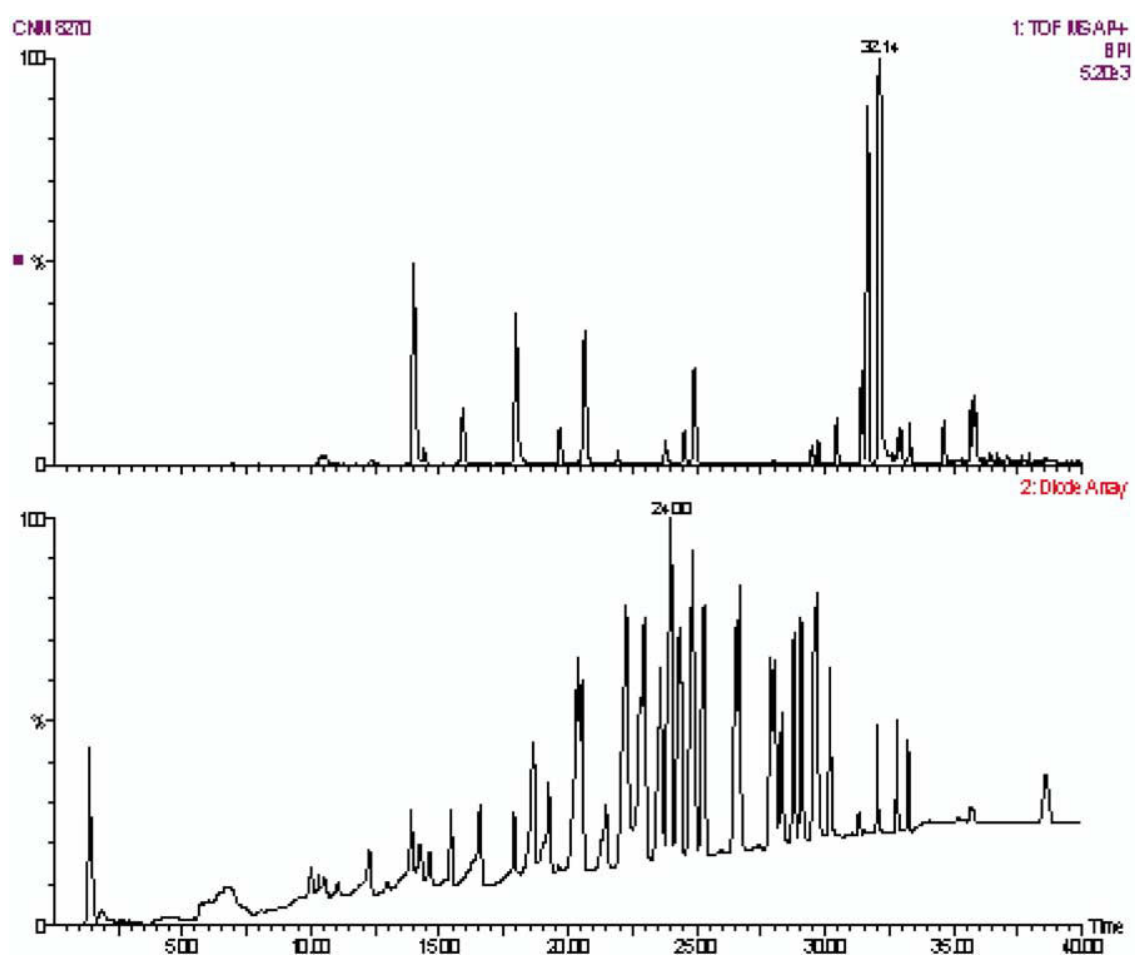

Figure 6. Base peak positive ion APCI LC/MS mass chromatogram using $5 \times$ the amount of Restek $8270^{\circ}$ mixture $^{\circ}$ injected ${ }^{\circ}$ for $^{\circ}$ the $^{\circ}$ spectra $^{\circ}$ shown $^{\circ}$ in $^{\circ}$ Figure $^{\circ} 1 .^{\circ}$ LC $^{\circ}$ conditions $^{\circ}$ were $^{\circ} 200^{\circ} \mathrm{ul} / \mathrm{min}^{\circ}$ water $/$ acetonitrile gradient using a $2.1 \mathrm{~mm} \times 150 \mathrm{~mm}{ }^{18} \mathrm{C}$ column. Top: LC base peak chromatogram of Restek 8270 mixture. Bottom: Diode array chromatogram.

for this sample. Clearly, for most of the compounds in the 8270 mixture, GC/APMS is more sensitive than LC/APMS under the conditions of these experiments. With this mixture, the same is true for electrospray LC/MS. This work demonstrates a clear advantage of having GC/APMS in addition to LC/MS capabilities.

Time-of-flight mass spectrometers are well suited for GC/APMS because of the fast data acquisition and the ability to obtain accurate mass measurement. With the Micromass QTOF and LCT mass spectrometers, after an initial calibration, a single reference ion can be used to adjust the mass scale and obtain good mass accuracy of all peaks in the spectrum. A reference standard can be constantly added to the ion source by allowing evaporation of a suitable compound to occur at a suitable rate. Tri-n-octylamine was allowed to evaporate from a partially enclosed vial placed in the ion source enclosure and the $\mathrm{MH}^{+}$ion at $\mathrm{m} / \mathrm{z} 354.4100$ was used as a single reference ion to adjust the pre-calibrated mass scale. Representative accurate mass measurement data using this $^{\circ}$ method $^{\circ}$ are $^{\circ}$ shown $^{\circ}$ in $^{\circ}$ Table $^{\circ} 1^{\circ}$ Because $^{\circ}$ of $^{\circ}$ the sharpness of the GC peaks, the measurements are of a single $0.5 \mathrm{~s}$ acquisition on a Micromass LCT. Mass accuracy is consistently within the instrument specifications for low-mass ions.

\section{Conclusions}

GC/APMS is best compared to chemical ionization GC/MS, and in the positive ion mode is shown to have comparable sensitivity. Superior negative ion sensitivity has previously been demonstrated in a series of papers dealing primarily with halogenated aromatic compounds using a dedicated GC/APMS instrument $[14,16,18,33] .{ }^{\circ}$ One $^{\circ}$ clear $^{\circ}$ advantage ${ }^{\circ}$ of ${ }^{\circ}$ interfacing ${ }^{\circ}{ }^{\circ} \mathrm{GC}$ to an atmospheric pressure ion source is the ease of interconversion between GC/MS and LC/MS. Other advantages are a wide range of carrier gas flow rates without affecting the atmospheric pressure ionization process. Higher carrier gas flow rates increase the speed

Table 1. Accurate mass measurement of GC/APMS eluted compounds using the $\mathrm{MH}^{+}$ion of trioctylamine (354.4100) as a reference standard.

\begin{tabular}{lcccc}
\hline \multicolumn{1}{c}{ Compound } & Elemental composition & Meas mass & Calc mass & MDa error \\
\hline \hline Methyl cyclohexanone & C7H130 & 113.0928 & 113.0966 & -3.8 \\
Benzamide & C7H8NO & 122.0593 & 122.0606 & -1.2 \\
2-Chlorophenol & C6H5OCl & 128.0023 & 128.0029 & -0.6 \\
Dioctylamine & $\mathrm{C} 16 \mathrm{H} 36 \mathrm{~N}$ & 242.2821 & 242.2848 & -2.6 \\
Polypropylene glycol (8-mer) & $\mathrm{C} 16 \mathrm{H} 35 \mathrm{O}$ & 371.2250 & 371.2281 & -3.1 \\
\hline
\end{tabular}


of analysis or, by using shorter columns of wide bore, less volatile compounds can be made to pass through the GC and be analyzed. In addition, all of the capabilities common with LC/MS instruments such as highresolution and accurate mass measurement, cone voltage fragmentation, $\mathrm{MS}^{\mathrm{n}}$, and reaction ion monitoring can be applied to GC/APMS. Disadvantages of GC/ APMS include the low abundance of odd-electron fragmentation for computer aided compound identification and poor ionization efficiency for nonpolar compounds having little or no functionality such as saturated hydrocarbons.

GC/APMS combined with LC/MS also has a number of advantages relative to dedicated LC/APMS instrumentation. Advantages include efficient ionization of volatile low polarity compounds and higher chromatographic resolution. Over 300 compounds can be determined ${ }^{\circ}$ from $^{\circ} \mathrm{a}^{\circ}$ single $^{\circ}$ sample $^{\circ}$ using $^{\circ} \mathrm{GC} / \mathrm{MS}^{\circ}$ [34] . These advantages are especially important for complex mixtures such as those encountered in environmental and metabolomic analyses. Other advantages of GC/ APMS versus LC/MS include few solubility issues and the simplicity of method development. It is now possible to have a mass spectrometer capable of LC/APMS, GC/APMS, and AP-MALDI.

\section{References}

1. Kitson, F. G.; Larsen, B. S.; McEwen, C. N. Gas Chromatography and Mass Spectrometry a Practical Guide; Academic Press: New York, 1996.

2. Sheehan, T. L. The best MS Option: GC-MS and LC-MS. Am. Lab. 2002, September, 40-43.

3. Felton, J. F. GC and Systems Biology. Today's Chemist at Work 2004, 13, 26-29.

4. Horning, E. C.; Carroll, D. I.; Dzidic, I.; Haegele, K. D.; Horning, M. G.; Stillwell, R. N. Atmospheric Pressure Ionization Mass Spectrometry, Solvent-Mediated Ionization of Samples Introduced in Solution and in a Liquid Chromatograph Effluent System. J. Chromatogr. Sci. 1974, 12, 725-729.

5. Whitehouse, C. M.; Dreyer, R. N.; Yamashita, M.; Fenn, J. B. Electrospray Interface for Liquid Chromatographs and Mass Spectrometers. Anal. Chem. 1985, 57, 675-679.

6. Carroll, D. I.; Dzidic, I.; Stillwell, R. N.; Haegele, K. D.; Horning, E. C. Atmospheric Pressure Ionization Mass Spectrometry: Corona Discharge Ion Source for Use in a Liquid Chromatography-Mass Spectrometry-Computer Analytical System. Anal. Chem. 1975, 47, 2369-2373.

7. Robb, D. B.; Covey, T. R.; Bruins, A. P. Atmospheric Pressure Photoionization: An Ionization Method for Liquid Chromatography-Mass Spectrometry. Anal. Chem. 2000, 77, 3653-3659.

8. Cappiello, A.; Balogh, M.; Famiglini, G.; Mangani, F.; Palma, P. An Efficient Liquid Chromatography-Mass Spectrometry Interface for the Generation of Electron Ionization Spectra. Anal. Chem. 2000, 72, 3841-3846.

9. Horning, E. C.; Horning, M. G.; Carroll, D. I.; Dzidic, I.; Stillwell, R. N. New Picogram Detection System Based on a Mass Spectrometer with an External Ionization Source at Atmospheric Pressure. Anal. Chem. 1973, 45, 936-943.

10. Horning, E. C.; Carroll, D. I.; Dzidic, I.; Haegele, K. D.; Lin, S.-N.; Oertil, C. V.; Stillwell, R. N. Development and Use of Analytical Systems Based on Mass Spectrometry. Clin. Chem. 1977, 23, 13-21.
11. Dzidic, I.; Carroll, D. I.; Stillwell, R. N.; Horning, E. C. Comparison of Positive Ions formed in Nickel-63 and Corona Discharge Ion Sources Using Nitrogen, Argon, Isobutene, Ammonia, and Nitric Oxide as Reagents in Atmospheric Pressure Ionization Mass Spectrometry. Anal. Chem. 1976, 48, 1763-1768.

12. Mitchum, R. K.; Korfmacher, W. A.; Moler, G. F.; Stalling, D. L. Capillary Gas Chromatography / Atmospheric Pressure Negative Chemical Ionization Mass Spectrometry of 22 Isomeric Tetrachlorodibenzo-p-Dioxins. Anal. Chem. 1982, 54, 719-722.

13. Mitchum, R. K.; Moler, G. F.; Korfmacher, W. A. Combined Capillary Gas Chromatography/Atmospheric Pressure Negative Chemical Ionization/Mass Spectrometry for the Determination of 2,3,7,8-Tetrachlorodibenzo-p-Dioxin in Tissue. Anal. Chem. 1980, 52, 2278-2282.

14. Korfmacher, W. A.; Rushing, L. G.; Engelbach, R. J.; Freeman, J. P.; Djuric, Z.; Fifer, E. K.; Beland, F. A. Analysis of Three Aminonitropyrene Isomers via Fused Silica Gas Chromatography Combined with Negative Ion Atmospheric Pressure Ionization Mass Spectrometry. J. High Resolut. Chromatogr., Chromatogr. Commun. 1987, 10, 43-45.

15. Korfmacher, W. A.; Rushing, L. G. Analysis of Seven Nitronaphthalene Compounds via Fused Silica Gas Chromatography Combined with Negative Ion Atmospheric Pressure ionization Mass Spectrometry. J. High Resolut. Chromatogr., Chromatogr. Commun. 1986, 9, 293-295.

16. Korfmacher, W. A.; Rushing, L. G.; Arey, J.; Zielinska, B.; Pitts, J. N., Jr. Identification of Mononitropyrenes and Mononitrofluoranthenes in Air Particulate Matter via Fused Silica Gas Chromatography Combined with Negative Ion Atmospheric Pressure Ionization Mass Spectrometry. J. High Resolut. Chromatogr., Chromatogr. Commun. 1987, 10, 641-646.

17. Korfmacher, W. A.; Rowland, K. R.; Mitchum, R. K.; Daly, J. J.; McDaniel, R. C.; Plummer, M. V. Analysis of Snake Tissue and Snake Eggs for 2,3,7,8-Tetrachlorodibenzo-p-Dioxan via Fused Silica GC Combined with Atmospheric Pressure Ionization MS. Chemosphere 1984, 13, 1229-1233.

18. Korfmacher, W. A.; Rushing, L. G.; Arey, J.; Zielinska, B.; Pitts, J. N., Jr. Identification of Mononitropyrenes and Mononitrofluoranthenes in Air Particulate Matter via Fused Silica Gas Chromatography Combined with Negative Ion Atmospheric Pressure Ionization Mass Spectrometry. J. High Resolut. Chromatogr., Chromatogr. Commun. 1988, 11, 288.

19. Engelbach, R. J.; Korfmacher, W. A.; Rushing, L. G. Analysis of Nitropyrenamines and Methylated Nitropyrenamines via Gas Chromatography-Negative Ion Atmospheric Pressure Mass Spectrometry. J. High Resolut. Chromatogr., Chromatogr. Commun. 1988, 11, 661-663.

20. Kinouchi, T.; Miranda, A. T. L.; Rushing, L. G.; Beland, F. A.; Korfmacher, W. A. Detection of 2-Aminofluorene at Femtogram Levels via High-Resolution Gas Chromatography Combined with Negative Ion Atmospheric Pressure Ionization Mass Spectrometry. J. High Resolut. Chromatogr., Chromatogr. Commun. 1990, 13, 281-284.

21. Mitchum, R. K.; Korfmacher, W. A.; Freeman, J. P. An Atmospheric Pressure Ionization Source for a Finnigan-MAT 4000 Mass Spectrometer. Anal. Instrum. 1986, 15, 37-50.

22. Siegal, M. W.; McKeown, M. C. Ions and Electrons in the Electron Capture Detector: Quantitative Identification by Atmospheric Pressure Ionization Mass Spectrometry. J. Chromatogr. 1976, 122, 397.

23. Reid, N. M.; Buckley, J. A.; Pom, C. C.; French, J. B. Adv. Mass Spectrom. 1980, 8B, 1843.

24. Lave, D. A.; Thompson, A. M.; Lovett, A. M.; Reid, N. M. Adv. Mass Spectrom. 1980, 8B, 1480.

25. Siegal, M. W.; Fite, W. I. Terminal Ions in Weak Atmospheric Plasmas. Applications of Atmospheric Pressure Ionization to 
Trace Impurity Analysis in Gases. J. Phys. Chem. 1976, 80, 2871-2881.

26. Charles, L.; Riter, L. S.; Cooks, R. G. Direct Analysis of Semivolatile Organic Compounds in Air by Atmospheric Pressure Chemical Ionization Mass Spectrometry. J. Agric. Food Chem. 2000, 48, 5389-5395.

27. Snyder, A. P.; Kremer, J. H.; Mouzelaar, H. L. C.; Windig, W.; Taghizahed, K. Curie-Point Pyrolysis Atmospheric Pressure Chemical Ionization Mass Spectrometry: Preliminary Performance Data for Three Biopolymers. Anal. Chem. 1987, 59, 1945-1951.

28. Steiner, W. E.; Clowers, B. H.; Haigh, P. E.; Hill, H. H. Secondary Ionization of Chemical Warfare Agent Simulants: Atmospheric Pressure Ion Mobility Time-of-Flight Mass Spectrometry. Anal. Chem. 2003, 75, 6068-6076.

29. Nikolaev, E.; Riter, L. S.; Laughlin, B. C.; Handberg, E.; Cooks, R. G. Trace Analysis of Organics in Air by Corona Discharge Atmospheric Pressure Ionization Using an Electrospray Ionization Interface. Eur. J. Mass Spectrom. 2004, 1, 197-204

30. Tyrefors, L. N.; Moulder, R. X.; Markides, K. E. Intrerface for Open Tubular Column Supercritical Fluid Chromatography/
Atmospheric Pressure Chemical Ionization Mass Spectrometry. Anal. Chem. 1993, 65, 2835-2840.

31. Sandra, P.; Medvedovici, A.; Ahao, Y.; David, F. J. Characterization of Triglycerides in Vegetable Oils by Silver-Ion Packed-Column Supercritical Fluid Chromatography Coupled to Mass Spectroscopy with Atmospheric Pressure Chemical Ionization and Coordination Ion Spray. J. Chromatogr. A 2002, 974, 231-241.

32. Schmeer, K.; Nicholson, G.; Zhang, S. G.; Bayer, E.; BohningGaese, K. Identification of the Lipids and the Ant Attractant 1,2-Dioleoylglycerol in the Arils of Commiphora guillaumini Perr. (Burseraceae) by Supercritical Fluid ChromatographyAtmospheric Pressure Chemical Ionization Mass Spectrometry. J. Chromatogr. A 1996, 727, 139-146.

33. Korfmacher, W. A.; Rushing, L. G. Determination of Seven Nitronapthalene Compounds via Fused Silica Gas Chromatography Combined with Negative Ion Atmospheric Pressure Ionization Mass Spectrometry. J. High Resolut. Chromatogr., Chromatogr. Commun. 1986, 9, 293-295.

34. Jonsson, P.; Gullberg, J.; Nordstrom, A.; Kusano, M.; Kowalczyk, M.; Sjostrom, M.; Moritz, T. A Strategy for Identifying Differences in Large Series of Metabolomic Samples Analyzed by GC/MS. Anal. Chem. 2004, 76, 1738-1745. 